\title{
Team-taught versus individually taught undergraduate education: a qualitative study of student experiences and preferences
}

\author{
Arthur Money ${ }^{1} \cdot$ Jane Coughlan $^{1}$
}

Published online: 25 January 2016

(C) The Author(s) 2016. This article is published with open access at Springerlink.com

\begin{abstract}
Team teaching is becoming more common in undergraduate programmes of study although the relative merits to the more traditional individually taught courses have not been determined for best practice. For this study, 15 final-year undergraduate computer science students were interviewed to gain insight into their learning experiences. A thematic analysis of the interview data identified the perceived advantages and disadvantages of each mode of teaching. The advantages of individually taught courses included: consistency of content delivery and advice, familiarity with the lecturer's teaching style and better continuity of the subject content. The disadvantage of individually taught modules included missing knowledge, compared to a team approach. Advantages of team-taught modules included: greater insight into a topic delivered by multiple team members. Disadvantages included: content overlap, conflicting messages relating to assessment, team members not taking ownership of their roles and responsibilities and a belief that overall team failure is worse than individual failure to deliver a module well. The results revealed that individually taught modules were generally preferred to team-taught modules. A set of best practice recommendations are proposed to address the challenges when delivering team-taught teaching and become more student focused.
\end{abstract}

Keywords Team teaching $\cdot$ Student perceptions $\cdot$ Computer science $\cdot$ Undergraduate

Arthur Money

Arthur.Money@brunel.ac.uk

Jane Coughlan

Jane-Lisa.Coughlan@brunel.ac.uk

1 Department of Computer Science, Brunel University, Kingston Lane, Uxbridge UB8 3PH, UK 


\section{Introduction}

Within the higher education context, team teaching is common place (Helms and Alvis 2005), but its relative effectiveness is highly dependent upon effective collaboration between team members across the duration of a course (Topping 1996; Yanamandram and Noble 2006). It is widely accepted that learning within the computer science domain often benefits from being active and collaborative, whereby important elements of programming, for example, are learnt via a range of methods including providing students with the opportunity to practise and apply their programming skills within laboratory sessions and via team-based tasks and exercises (Tirronen and Isomöttönen 2011; Vihavainen et al. 2011; Park and Choi 2014). However, less is known about whether there are benefits to adopting more collaborative team teaching-based approaches over more traditional individual instructor-led approaches to course content delivery within the computer science domain. In the existing literature, the term 'team teaching' can broadly be associated with one of three forms: (1) simultaneously taught content which involves two or more academic practitioners present during each session (co-teaching approach); (2) one academic practitioner being present in each session, but taking it in turns to deliver sessions between two or more people over the duration of the course (tag rotation approach); and (3) a combination these two models (hybrid approach) (Dugan and Letterman 2008). Guest lectureships may also feature as form of team teaching, but has been found difficult to evaluate (Jacob et al. 2002). The tag rotation approach (TRA), i.e. requiring one academic practitioner to be present at a time, is perhaps the most commonly used form of team teaching in higher education (Murawski 2005). Some advantages of TRA, from the academic institution/academic practitioner perspective, include the ability to align content delivery more closely to the academic practitioner's expertise and existing knowledge base. From the perspective of the student, TRA allows exposure to emerging knowledge in different topic areas and the opportunity to assimilate knowledge from different viewpoints (Hanusch et al. 2009). Comparatively, TRA delivers further efficiencies in terms of the overhead required to become familiar with/mastering the content before delivering it. Modules delivered using the TRA approach also allow the institution to more readily be able to deliver cross-disciplinary courses, which widens the portfolio of courses on offer and allows the institution to remain competitive within a fast changing market place (Otzinger 2004).

Despite the benefits that TRA delivers from the academic and student perspective, little research has been carried out to explore how module content delivered in this format is experienced from the student perspective (Feingold et al. 2008). Certainly, when considering the domain of Computer Science, there do not appear to be any published studies that consider the student perspective of TRA compared with other modes of delivery. Few studies exist that explicitly evaluate student reported experiences of courses delivered by one faculty member compared with TRA, or indeed any of the other forms of and team teaching (co-teaching and hybrid approaches). When considering studies outside of the computer science domain, Colburn et al. (2012) have explicitly evaluated student reported experiences of individually taught courses compared with team TRA and collaborative/co-teaching approaches. They found that there was no statistically significant difference in terms of preference between coteaching and individually taught courses; however, in absolute terms, co-taught courses achieved higher absolute values and were preferred by students. Interestingly, team-taught courses (TRA with three or more members) in statistical significance terms scored lower than courses delivered using the co-teaching approach. Other relevant works that consider the student perspective to some extent have been more focused specifically on the benefits of coteaching, i.e. delivering content by more than one academic practitioner within the same 
session. Colburn et al. (2012) found that co-teaching had a positive impact on students with low GPAs and improved their performance. Some benefits of co-teaching reported by students have included the feeling that teacher-student relationships were improved using this approach (Wilson and Martin 1998) and that improved levels of learning are achieved as a result of more reflective and collaborative means of content delivery (Benjamine 2000). It has also been found that students reported that they felt more able to link content from multiple disciplines together and that they tended to retain information for longer as a result of being able to experience real-time discussion with experts that engaged in cross-disciplinary inclass debates (Johnson et al. 2000; Otzinger 2004).

Given that TRA is a common form of team teaching delivery within higher education settings (Murawski 2005), it is important that student experiences of this model of content delivery are better understood. Coupled with the lack of research which exists to explore student perspectives within the computer science domain, there is a need to explore and better understand student perspectives to understand the conditions under which the learning environment can be enhanced. In particular, it is important to understand student experiences of the relative advantages and disadvantages of this model of content delivery, compared with the more traditional single faculty member delivery model. Gaining detailed insights into the relative advantages of TRA compared with individual faculty delivery models will serve as a means of better informing teaching practice and identifying best practice recommendations to address the issues identified by students who have engaged in both modes of content delivery.

\section{Methods}

\section{Participants}

A total of 15 participants were recruited: all males and aged between 20 and 27 years. Table 1 presents the age, gender and student registration status of each respective that took part in this study.

Table 1 Participant details

\begin{tabular}{llll}
\hline Participant no. & Gender & Age & Home/overseas student \\
\hline$\# 1$ & Male & 22 & Home \\
$\# 2$ & Male & 23 & Home \\
$\# 3$ & Male & 21 & Home \\
$\# 4$ & Male & 20 & Home \\
$\# 5$ & Male & 21 & Home \\
$\# 6$ & Male & 27 & Home \\
$\# 7$ & Male & 22 & Home \\
$\# 8$ & Male & 22 & Home \\
$\# 9$ & Male & 21 & Home \\
$\# 10$ & Male & 24 & Home \\
$\# 11$ & Male & 21 & Home \\
$\# 12$ & Male & 22 & Home \\
$\# 13$ & Male & 21 & Home \\
$\# 14$ & Male & 22 & Home \\
$\# 15$ & Male & 23 & Home \\
\hline
\end{tabular}


A convenience sampling strategy was used to identify participants eligible to take part in this study (King 2004; Hair et al. 2007). The inclusion criteria were third-year undergraduate students within the Department of Computer Science who had experience of having engaged with study on modules which were delivered by one individual throughout and modules that had been taught by a team of academic practitioners conforming to the TRA model approach throughout their undergraduate studies. A 'snowball' recruitment strategy was used (Noy 2008). In the first instance, staff colleagues of the investigator were asked to mention the study to final-year project (FYP) students under their supervision. Staff made it clear that there was no obligation to take part in the research and that taking part would have no bearing on their programme of academic study or any assessment related to this. Students were asked to contact the investigator, if they were interested in taking part (not including students directly under the authors' supervision). Recruitment of participants for interview ceased with data saturation (Braun and Clarke 2006; Walker 2012), that is, when the researcher leading the analysis observed a clear pattern emerging in participant responses and subsequent responses appeared to become repetitious with no new themes being identified (Guest et al. 2006).

\section{Course content and mode of delivery}

The typical course content delivered on the undergraduate computer science programme is made up of four modules per year as well as a group project in years 1 and 2, and a finalyear project in year 3 . Table 2 presents the typical course content and module titles as well as the mode of delivery for each of these modules.

As can be seen, there is a mix of delivery modes throughout the 3 years of undergraduate study. In each year, students experience individually delivered modules as well as TRA and hybrid delivery modes. The most common of these is TRA, with a total of seven modules being delivered in this mode. A total of five modules are delivered in the individual mode, and three modules are delivered using the hybrid approach.

Table 2 Typical course content of undergraduate computer science programme

\begin{tabular}{lll}
\hline Year of study & Module & Mode of delivery \\
\hline Year 1 & Introductory programming & TRA \\
& Data and information & Individual \\
& Information systems and organisations & Individual \\
& Logic and computation & TRA \\
& Group project & Hybrid \\
Year 2 & Software development and management & TRA \\
& Usability engineering & TRA \\
& Algorithms and their applications & TRA \\
& Networks and operating systems & Individual \\
& Group project & Hybrid \\
Year 3 & Software project management & TRA \\
& Networking & Individual \\
& Digital media and games & Individual \\
& Advanced topics in computer science & TRA \\
& Final-year project & Hybrid
\end{tabular}




\section{Semi-structured interviews}

In-depth semi-structured interviews were conducted on a one-to-one basis with each participant. Consent was obtained to record interviews with a digital voice recorder. In the interview, participants were asked to discuss their experiences as a student on a module that was delivered by one individual and on a team-taught module (rotation approach with three or more team members). Participants were also asked to discuss the strengths and weaknesses (Ansoff 1987) associated with each of these teaching approaches and to compare and contrast the experiences and to conclude with which they preferred overall. Interviews durations varied between 28 and $60 \mathrm{~min}$. Template analysis was used to analyse the interview data. This is a form of thematic analysis, which involves development of a coding template that represents a summary of the themes that are seen by the researcher(s) as being of importance within the data set (King 2004). Analysis often begins with some a priori themes/codes that are of interest to the researcher; in this case, the interview data were approached with the broad aim of exploring the perceived strengths and weaknesses as seen by students of each of the modes of module delivery. Therefore, the approach taken in the analysis of this data is in line with what Madill et al. (2000) refer to as the 'contextual constructivist' position. In this case, the focus of the researcher was specifically focused on discussing student experiences of TRA versus individual faculty delivery models; hence, it is important to bear in mind that the themes that emerge as a result of the analysis should be accepted as being partly a product of the researcher's focus on these factors (Marton and Booth 1997).

\section{Data analysis and coding procedure}

The recorded data set, in its entirety, was perused to conceptualise the overarching themes that existed at a high level. The data set was then perused for a second time, and sections of the dialogue that corresponded with the focus of the research questions were initially colour-coded by highlighting text within the respective transcripts. This process was carried out for the first three of the 15 interviews, after which a number of overarching themes representing the content within and across interviews were proposed as an initial coding template. A separate coding template document was then created to host the initial emergent themes and segments of dialogue that corresponded with new themes as well as a priori themes which were copied into this document along relevant metadata such as the respective participant ID, page and line number from which it was sourced. The remainder of the data set was then examined iteratively, enabling themes and sub-themes to be developed and modified as a result of carefully considering the contents of each interview. This was achieved via an iterative process of cutting and splicing relevant text from the transcript documents into the template document and iteratively reflecting and reorganising its content and associated themes and sub-themes. This process was carried out by the investigator, until a clear consensus of the main themes was reached (Braun and Clarke 2006). When no further refinement of the categorisation could be derived, a final template representing the themes and sub-themes identified within the full data set was produced. All content within the coding template document was clearly linked to the words of the respondents within the interview transcripts via the participant ID and page and line numbers as they were presented in interview. For a detailed description of the thematic template analysis process, see King (2004), and similarly for the thematic analysis process, see Joffe and Yardley (2004) and Silverman (2005). 


\section{Results}

\section{Student experiences}

The thematic analysis of the interviews revealed a number of high-level themes and associated sub-themes (see Fig. 1). These will now be presented within the overarching template used to consider the results: advantages and disadvantages of each respective mode of teaching and team taught and individually taught. In order to maintain anonymity of members of faculty who delivered the respective modules delivered on the undergraduate programme, module names have been removed from participant quotes in this section.

\section{Individual taught: advantages}

\section{Consistency}

The majority of students stated that they appreciated individually taught modules more than team-taught modules. Some of the key drivers for this choice were that they felt that they were able to learn what the lecturer required from them over a longer period of time and hence felt more able to deliver this in assessed coursework and in the examination. It seemed that the desire to deliver what the lecturer wanted was of top priority to students as was the desire to achieve high grades on the module, as opposed to maximising the amount of learning that was achieved throughout the duration of the module. Consequently, getting to know what the lecturer required from them would improve their chances of achieving a higher grade. The following quote articulates this point:

I would rather just stick to one person, university is about individual learning as well.

So I would just have one person, lecturers will give you basic information and then do my own research and reading around what they have said instead of getting three different sets of information and then getting even more information yourself...you will get a better grade like that...with different people you get different opinions so you don't know which one to follow...in the exam. Participant \#3.

There was also a feeling that module content appears to be more cohesive and consistent when one lecturer delivers it. There was a feeling that multiple lecturers sometimes appeared to be less focused on an overriding narrative which sits and links an entire module together, and hence, individual lecturers were more aware of how content delivered week to week fitted within the higher-level narrative. Overall, the feeling was that modules delivered by one individual seemed to benefit from being more consistent in terms of focus and alignment of the content with an overriding narrative. Overall, students appeared to prefer this more 'stable' approach as is demonstrated in the two quotes below:

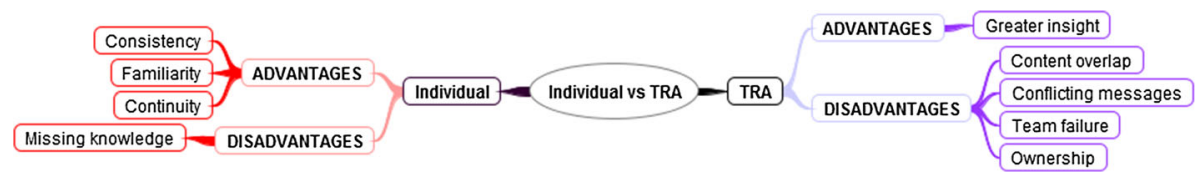

Fig. 1 Thematic mind map of individual and TRA themes and sub-themes 
Of course one lecturer, it's much better than the one with 5 lecturers -it's too much (5 lecturers), the one lecturer knows what he is doing. Participant \#9.

Fewer is better, just because of consistency. Participant \#1.

\section{Familiarity}

In terms of varying style of lecturers, students tended to prefer modules that were delivered by a single lecturer. One of the key reasons for this was that they felt that consistently seeing the same lecturer week to week allowed students to become familiar with the teaching style and in some way overcome the overhead that is involved in orientating oneself to an individual teaching style. This allowed students to then focus more on the content as opposed to having to expend effort on becoming used to new teaching styles throughout the course of a module:

I prefer to have one person and get used to just that one person... It's just the teaching style, you get used to the teaching style and you don't want it to change. Participant \#3.

Further considering the preference for maintaining one teaching style throughout, some students assumed that in general, members of staff know their subject and hence should be capable of delivering all the content. Having multiple members of a team delivering a module caused unnecessary confusion and furthermore encouraged students to develop a bias towards one lecturer over others and as a consequence paying less attention to those lecturers that are not considered to be delivering content as effectively as others:

I personally prefer a single lecturer, assuming they know their topic which they should do, I prefer the consistency of a single person, seeing as you get used to how they convey information and when you have multiple lecturers it gets a bit confusing you grow a bias towards one of the lecturers and don't take much notice of what the other lecturers are saying. Participant \#11.

\section{Continuity}

Another key advantage of individually delivered lectures was perceived to be the continuity that seeing the same person each week affords. In particular, it was noted that sometimes a topic may not have been completed in one lecture and hence can be picked up in the following weeks lecture. Students also felt that it is easier to ask questions within the lecture if the students feel more familiar with the lecturer and their style. They may also be able to ask questions that link content that perhaps was delivered in previous sessions and relate it to the content that is being delivered within that session. This is more difficult to do if a new lecturer is delivering content.

If you don't cover something one week, you can come back to it the next week and you can ask questions...it's better having deep learning from one than lots of topics from lots of lecturers. Participant \#7.

Furthermore, the weekly content that is delivered seems to follow on more from previous lectures when delivered by one lecturer and hence offers continuity and presents the impression that the module been more thoroughly thought through. 
A module delivered by one lecturer seems to be more well thought out and they fit together. Participant \#4.

\section{Individual taught: disadvantages}

\section{Missing knowledge}

In general, during interviews, students found it difficult to think of the disadvantages of individually taught modules. When probed, however, it was suggested that in some instances only one lecturer may not be able to share as much knowledge as multiple lecturers.

You might miss out on some knowledge with only one lecturer. Participant \#12.

This theme touches on similar topics considered within the Consistency theme, relating to missing out on knowledge as a consequence of only being taught by one lecturer. Where, relating to Consistency, students reported that missing out knowledge may be a price worth paying if the end result meant achieving higher grades overall by being able to learn one lecturer's point of view and demonstrate knowledge that is in line with this view when being assessed.

\section{TRA taught: advantages}

\section{Greater insight}

Students appeared to be somewhat less forthcoming when questioned about the perceived advantages of team-taught delivery of module content. There were, however, some perceived advantages. One advantage, which was made with the caveat that lectures are delivered cohesively (i.e. the content follows on from week to week and that lecturers are aware of the content that has been covered previously), was that multiple lecturers were likely to provide multiple viewpoints on the content delivered which was likely to improve the learning experience:

If they have good cohesion between multiple lecturers then you will able to probably get a greater insight into the content of the module. Participant \#1.

Another potential advantage of team-taught modules was that students have a greater chance of understanding some of the team if the lecturers are varied. This is exemplified by the following quote:

Sometimes if you don't understand one, you might understand the other. Participant $\# 14$.

One student mentioned team-taught modules tended to cover more topics, which may be of benefit when entering the workplace after university. Interestingly, learning at university appeared to be viewed as a separate issue to performing in a workplace, and hence, it was concluded that one lecturer was preferable within the university setting. This offers an interesting insight into whether students consider the learning that occurs within the university context as serving the function of providing them with skills within the workplace or indeed whether they are more motivated to prioritise the application of learned content via assessment within the university context. Indeed, it would seem that students often subscribe to the latter scenario as being of top priority, and any added value that this may deliver within the workplace as being an added bonus but is not considered as a priority as is exemplified below: 
I think the multiple lecturers will help me more when I go to work because we cover more topics...but one lecturer is better for learning at university. Participant \#6.

\section{TRA taught: disadvantages}

\section{Content overlap}

One of the key observations was that team-taught modules suffered from containing too much content. In some cases, it seemed as if each member of the teaching team was trying to cram as much of what they know into their lecture slots, perhaps as a result of only having a few slots to deliver all of their content within. This also seems to link to the notion that individually taught modules tend to benefit from continuity as described in the previous section. One participant commented:

With lots of lecturers it's too much, each lecturer wants to give everything he knows in one lecture. Participant \#9.

It was also felt that in addition to too much new content being delivered that duplication of content was also an issue. It was felt that sometimes individual members of the team were unaware of what had been covered by colleagues and hence often duplicated content. This was seen as a waste of the students' time, although students recognised that summarising content that had been previously covered had some valuable function; it did not appear as if members of the team were aware of what had been covered previously. The two quotes below exemplify some of the opinions shared on this matter:

We found that with [module name] in these lectures you only have an hour or two really, and what I found was that someone taught something one week and then the next week there was a different lecturer who taught the same thing, so it's sort of a waste of, well not both of those hours, but at least one of those hours. Participant \#1.

A team that is not well co-ordinated does not really have a holistic picture of how the course fits together as a whole and each individual team member does not know how the part of the course that they are delivering relates to the other bits of the course and also whether the content they are delivering has been delivered already...it creates a confusion throughout the core of the module. Participant \#10.

\section{Conflicting messages}

In terms of the overall management of the module and advising students on matters relating to coursework and examinations, teaching teams appeared to often provide conflicting advice. It was felt that it is important to manage and minimise the occurrence of these issues by clearly defining each member of the team's role and making this clear to the students. An example of this being implemented effectively is provided below:

For instance, I believe [module name] did that well, since one lecturer handled everything lecture based and one lecturer handled everything laboratory and seminar and coursework based. It was good because we knew where to question. On lots of the other modules you don't know where or who to ask. Participant \#1. 


\section{Team failure}

More generally, reflecting upon the team-taught experience, it was felt that when a team fails to deliver a module well, it seems to have much more of a negative impact on students compared with an individually taught module. Furthermore, it seems more understandable and easier to accept if the failing is by one individual as opposed to a team of individuals, as is articulated below:

It's so much worse when a team fails to deliver a module well, take [module name] for example, you have a team of individuals who are clearly experienced in the field not able to communicate well with each other to deliver the module effectively that's an entire team of people failing to do what they do. If it's just one person it's more forgivable. Participant \#5.

\section{Ownership}

Students felt that often members of a team did not take ownership of the content they delivered, perhaps as they did not take personal responsibility for the content that was being delivered. Consequently, the lecture materials sometimes appeared outdated, lacked focus and clearly appeared to be unadapted content from previous years. Also linked to the notion of lack of co-ordination of the team, the same errors are made multiple times by different members. Furthermore, as a function of there being many team members each having their own lecturing style, a wider variety of errors are made over the duration of the module which sometime gives the impression of there being a wider variety of issues than would be perceived when one person delivers the content, as is described below:

They will give a lecture and it was obviously reused from the previous year, because they haven't vetted it and they will be like 'ooops that shouldn't have been there' I believe a lot of the things that makes a group (team teaching) less desirable is that the ripple effect is more prominent as these little errors build up over all these people and with the communication errors and all these little things it just builds up into a worse thing in my eyes because there are more holes. Whereas a single person can make the same mistakes but there are less holes in the education in general. Participant \#10.

Following on from the observation that team members sometimes do not appear to take ownership of the content they deliver, one participant appeared to make the assumption that team members tend to deliver other peoples content, perhaps supplied by the module leader. Consequently, team members were not able to deliver this content as effectively as the individual who developed the lecture materials:

One person delivering their own content is likely to relate to their content better than a team of people sometimes trying to teach someone else's content. Participant \#15.

The lack of taking ownership was also perceived as having an impact on the effectiveness of support provided on online discussion forums. It was felt that 'bystander syndrome' came into effect on team-taught modules which resulted in there being significant time delays in team members responding to comments perhaps as a result of none of the team members assuming responsibility to respond to student queries and discussion, as is articulated in the below comment:

Online discussion forums suffer from what I call bystander syndrome, which is essentially if one person collapses in pain and there is one person nearby that one 
person will help them, but if that same person collapses with 10 people nearby, no one will take the first step forward...relating that to discussion forums when there are lots of members of staff the replies are slow but on modules with less number of staff they will reply more quickly. Participant \#8.

\section{Discussion and recommendations}

This study has explored student experiences of team-taught and individually taught undergraduate modules delivered as part of a computer science undergraduate programme. Fifteen third-year undergraduate students were interviewed all of which had experience of individually taught and team-taught (TRA) modules delivered as part of their undergraduate study. A thematic analysis of the transcribed interview data revealed a number of themes that offered insight into the perceived advantages and disadvantages of delivering undergraduate content in the two respective teaching modes. Students felt that individually taught modules benefitted from consistency, and there appeared to be more continuity in terms of content delivered. Furthermore, 'Familiarity' with the lecturer and their teaching style was also felt to be a major benefit of individually taught modules. Some disadvantages included the potential for missing knowledge when delivered by one individual although this did not appear to be major concern for students particularly when considering that the assumption was made that they would only be examined on the knowledge that has been shared with them. Furthermore, it was questionable whether missing knowledge was of significance to students, particularly in the light of comments made relating to the previously presented theme of Consistency; students reported that missing knowledge was a reasonable price to pay if consistency in the delivery of the module was maintained. TRA advantages included some belief that greater insight into a topic could be achieved as a result of multiple faculty members delivering the content; however, there appeared to be many more disadvantages to this mode of teaching. Students felt that there was often content overlap and that they also received conflicting messages from different team members. It was also felt that team failure is worse than individual failure to deliver a module well. In particular, the ripple effect of multiple team members making multiple errors was perceived as worse than one individual making errors. It was suggested that perhaps one of the key reasons for team-taught modules not delivering high standards was team members not taking ownership of their role on the module which resulted in outdated content being delivered, members delivering other people's content and as a result of 'bystander syndrome', online discussion forums not being attended to in a timely manner.

Although there appear to be some advantages to adopting the team-taught mode from both a student and practitioner perspective, there appear to be a number of factors that must be addressed to ensure that module content is delivered in a way that benefits the student, which is in keeping with recent work (Lee 2013). In particular, a reoccurring theme that provided some explanations for the shortcomings of team-taught module delivery was the lack of co-ordination and management of the content and the team. In the absence of this co-ordination and management, team-taught modules tended to be perceived as lacking coherence, cohesiveness, focus and direct direction, duplicating content and lecturers were perceived as not taking ownership of their position. Although team teaching has the potential of delivering benefits over and above that of individually taught content, poorly delivered team-taught modules run the risk of being perceived being far less valuable than a poorly delivered individually taught module. Therefore, it is crucial that additional effort 
is put into ensuring team-taught content adheres to good practice in terms of management, co-ordination and appropriate content delivery. Indeed, similar insights relating to TRA have been identified in existing research studies carried out in the management training and journalism domains (Wenger and Hornyak 1999; Hanusch, Obijiofor et al. 2009). Both studies highlight the important role that preparation plays in achieving cohesiveness and continuity in content delivery. In the light of the issues identified in this study, Table 3 makes recommendations that, if adhered to, will help ensure more effective delivery of TRA delivery of modules. The recommendations are explicitly mapped to the themes identified as disadvantages of TRA in the previous section.

Assigning clearly defined roles to members of the team prior to its delivery would help to mitigate the issues relating to conflicting messages being given to students, for example, with regard to coursework requirements and the examination. It would serve as a point of reference not only for students, who would know which team member is responsible for which part of the assessment, but also for team members who could consult with the appropriate team member and point students to the correct point of contact when necessary. Assigning a clear definition of responsibilities for each role would provide an additional mechanism to ensure that each of the defined roles clearly have responsibilities associated with them. This would also be useful for students and team members who would have a better understanding of what they can expect from each other and once again point queries in the right direction. The critical importance of careful planning, close collaborative working, which includes the clear definition of responsibilities is also echoed and supported in numerous other team teaching focused studies (Shilbey 2006; Dugan and Letterman 2008; Nevina, Thousand et al. 2009; Coker 2014). Shilbey (2006), for example, highlights the importance of planning out team roles, clearly defining team member responsibilities and investing significant time and effort into planning as being key factors in successful delivery of team-taught course content.

Providing an overarching narrative that links all elements of the taught content together will ensure that students have a good comprehension of the focus of the module and how each lecture fits within this. The power of narrative and the value it brings content delivery has long been recognised within education settings (Carter 1993). Not least, the delivery of knowledge within a clear overarching narrative format enables complex and interrelated subject matter to be encapsulated within an powerful and intuitively structured form which can be accessed and understood across a wide range of learners (Lyons and LaBoskey 2002). From a teaching team perspective, encapsulating the full course content within an overarching narrative structure would help to ensure that each respective session fits within

Table 3 Recommendations for team teaching best practice

\begin{tabular}{lll}
\hline Recommendation & Target & Communicated to \\
\hline Clear definition of roles & $\mathrm{CM}, \mathrm{O}, \mathrm{TF}$ & Students and team \\
Clear definition of responsibilities & $\mathrm{CM}, \mathrm{O}, \mathrm{TF}$ & Students and team \\
One overarching narrative & $\mathrm{CO}, \mathrm{TF}$ & Students and team \\
Clearly partitioned subject matter (e.g. block content) & $\mathrm{CO}, \mathrm{TF}$ & Students and team \\
Clear awareness of what has already been taught & $\mathrm{CO}, \mathrm{TF}$ & Team \\
Clear awareness of coursework and examination requirements & $\mathrm{CM}, \mathrm{TF}$ & Team \\
Manage expectations-regarding change (lecturer and content) & $\mathrm{CO}, \mathrm{CM}, \mathrm{TF}$ & Students
\end{tabular}

$C O$ content overlap, $C M$ conflicting messages, $T F$ team failure, $O$ ownership 
this narrative and tells a unique and critical part of the higher-level story which holds the course together. This that would contribute towards ensuring content is not duplicated, and when delivered in conjunction with clearly partitioned subject matter, each sub-segment of the module will coherently sit within the higher-level narrative. Communicating a clearly defined high-level narrative which is complimented by subsections, for example segmenting the narrative into blocks, would serve as an additional point of reference for students and team members to ensure co-ordinated and complimentary subject content and help to ensure that content overlap only occurs intentionally.

Prior to delivery of individual lectures, team members should have clear awareness of what has already been taught to date. The module leader should also ensure that all team members have clear awareness of coursework and examination results and how the respective block content relates to these assessed tasks. Indeed, this is supported by existing research, which has found that maintaining effective communication between team members, as well as ensuring that all team members are fully engaged with the planning and design of a course, is crucial in the effective delivery of course content (Thousand et al. 2006; Nevina et al. 2009). Another important consideration is that change can be perceived as disruptive for students. One way of mitigating the disruptive nature of change is to manage expectations. In particular, intros and outros when new members of the team are scheduled to be delivering lectures the following week are essential in managing this change. Similarly, as a minimum, the week prior moving onto a new block of content, the lecturer should give advanced notice of this and prepare the students for the change in focus and orientate them as to how the change in focus shifts within the higherlevel narrative of the module. Existing research highlights the importance of managing student expectations, which, if done effectively, is likely to minimise the likelihood of encountering learning challenges that limit their capability to properly leverage their acquired competencies (Buckley et al. 2004). Hence, investing effort into effectively managing students' expectations over the lifespan of a course is a crucial factor to be considered if learning outcomes are to flourish (Fishera and Millera 2008).

\section{Conclusions}

This study explored student experiences, in terms of the advantages and disadvantages, of two modes of course content delivery individually taught and team-taught (TRA) course content delivered as part of their undergraduate Computer Science degree delivered as part of their undergraduate study. A thematic analysis of 15 transcribed interviews revealed that students felt that individually taught modules benefitted from being perceived as benefitting from having greater consistency and continuity. Furthermore, better familiarity with the lecturer was also seen as an advantage which lent itself to enabling students to focus more attention on grasping course content. The main advantage of TRA was seen to be the wider range of content that could be covered by multiple faculty members. However, TRA also sometimes resulted in duplicated and conflicting content being delivered. Overall, it was felt that whole courses delivered by individual members of faculty was preferable to courses being delivered using TRA as there was less risk of significant issues arising when delivered by individual members of faculty. As a result of the findings, a series of practice recommendations were presented, which, if followed, will help mitigate the risk of issues occurring when using the TRA mode delivery. Considering factors such as practicality, convenience, efficiency and the versatility gains that TRA promises from an academic 
practitioner's perspective, but not necessarily a student's perspective, it is nevertheless likely that TRA will continue to be a popular mode of teaching choice and delivery in the future despite the clear drawbacks to students highlighted in this study. If indeed this continues to be the case, it is important that academic practitioners recognise the potential drawbacks of such an approach and take heed of the findings of this study. Perhaps more importantly, academic practitioners would benefit from actioning the recommendations set out in this study so as to maximise the benefits to the students that may be realised by adopting the TRA approach. Therefore, the recommendations presented here are of crucial importance, which, if adhered to, are likely to improve the way in which TRA is perceived by, and delivered to, students. Future work will be focused around deploying the recommendations proposed in this study and evaluating the extent to which it has a positive impact on content delivered using the TRA approach within the Computer Science domain.

Author contributors Dr Arthur G. Money is a Lecturer in the Department of Computer Science at Brunel University, London. His research expertise lies in user-centred design and evaluation of interactive systems, specifically developed according to the requirements of users with complex needs across a range of domains including healthcare, older adults and multimedia systems. Dr Jane Coughlan is a Lecturer in HumanComputer Interaction at Brunel University, London. She is interested in User Experience (UX) and behaviour change in the area of persuasive design and creating technologies that influence or nudge people's decision-making processes in e-commerce and e-health contexts, in particular gamification and serious games for health. She also has an interest in social media for education, particularly in the relationship between social capital and employability for enhancing the student experience.

Open Access This article is distributed under the terms of the Creative Commons Attribution 4.0 International License (http://creativecommons.org/licenses/by/4.0/), which permits unrestricted use, distribution, and reproduction in any medium, provided you give appropriate credit to the original author(s) and the source, provide a link to the Creative Commons license, and indicate if changes were made.

\section{References}

Ansoff, H. I. (1987). Corporate strategy. London: Penguin Books.

Benjamine, J. (2000). The scholarship of teaching in teams: What does it look like in practice? Higher Education Research and Development, 19, 191-204.

Braun, V., \& Clarke, V. (2006). Using thematic analysis in psychology. Qualitative Research in Psychology, 3(2), 77-101.

Buckley, M. R., Novicevic, M. M., et al. (2004). Course management and students' expectations: Theory based considerations. International Journal of Educational Management, 18(2), 138-144.

Carter, K. (1993). The place of story in the study of teaching and teacher education. Educational Researcher, 22(1), 5-12.

Coker, T. (2014). Further education teachers' perceptions on collaboration. International Journal of Multidisciplinary Comparative Studies, 1(3), 38-53.

Colburn, M., Sullivan, D., et al. (2012). An examination of the impact of team teaching on student learning outcomes and student satisfaction in undergraduate business capstone courses. American Journal of Business Education 5(2).

Dugan, K., \& Letterman, M. (2008). Student appraisals of collaborative teaching. College Teaching, 56(1), $11-15$.

Feingold, C. E., Cobb, M. D., et al. (2008). Student perceptions of team learning in nursing education. Journal of Nursing Education, 47(5), 214-222.

Fishera, R., \& Millera, D. (2008). Responding to student expectations: A partnership approach to course evaluation. Assessment and Evaluation in Higher Education, 33(2), 191-202.

Guest, G., Bunce, A., et al. (2006). How many interviews are enough? An experiment with data saturation and variability. Field Methods, 18(1), 59-82.

Hair, J. F. J., Money, A. H., et al. (2007). Research methods for business. Chichester, England: Wiley.

Hanusch, F., Obijiofor, L., et al. (2009). Theoretical and practical issues in team teaching a large undergraduate class. International Journal of Teaching and Learning in Higher Education, 21(1), 66-74. 
Helms, M., \& Alvis, J. M. (2005). Planning and implementing team teaching: An MBA team-teaching case study. Journal of Education for Business, 8, 29-34.

Jacob, H. S., \& Honey, R., et al. (2002). Getting the most out of sequential teaching. In: 11th Teaching and Learning Forum. Perth, WA.

Joffe, H., \& Yardley, L. (2004). Content and thematic analysis. In D. F. Marks \& L. Yardley (Eds.), Research methods for clinical and health psychology (pp. 56-66). London: Sage Publications.

Johnson, D., Johnson, R. T., \& Smith, K. A. (2000). Constructive controvercy: The educative power of intellectual conflict. Change, 32(1), 29-37.

King, N. (2004). Using templates in the thematic analysis of text. In C. Cassell \& G. Symon (Eds.), Essential guide to qualitative methods in organizational research. London: Sage.

Lee, S. H. (2013). An evaluation on a team teaching by university students and lecturers in Australia. Journal of Language Teaching and Research, 4(5), 914-923.

Lyons, N. P., \& LaBoskey, V. K. (2002). Narrative inquiry in practice: Advancing the knowledge of teaching. New York: Teachers' College Press.

Madill, A., Jordan, A., et al. (2000). Objectivity and reliability in qualitative analysis: Realist, contextualist and radical constructionist epistemologies. British Journal of Psychology, 91, 1-20.

Marton, F., \& Booth, S. (1997). Learning and awareness. New Jersey: Erlbaum Associates.

Murawski, W. (2005). Addressing diverse needs through co-teaching: Take baby steps! Kappa Delta Pi Record, 41(2), 77.

Nevina, A. I., Thousand, J. S., et al. (2009). Collaborative teaching for teacher educators-What does the research say? Teaching and Teacher Education, 25(4), 569-574.

Noy, C. (2008). Sampling knowledge: The hermeneutics of snowball sampling in qualitative research. International Journal of Social Research Methodology, 11(4), 327-344.

Otzinger, J. H. (2004). Integrating modern times through student team presentations: A case study on interdisciplinary team teaching and learning. College Teaching, 53, 64-68.

Park, E. L., \& Choi, B. K. (2014). Transformation of classroom spaces: Traditional versus active learning classroom in colleges. Higher Education, 68(5), 749-771.

Shilbey, A. (2006). Interdisciplinary team teaching: Negotiating pedagogical differences. College Teaching, 54(3), 271-274.

Silverman, D. (2005). Doing qualitative research. London: Sage Publications.

Thousand, J. S., Villa, R. A., et al. (2006). The many faces of collaborative planning and teaching. Theory Into Practice, 45(3), 239-248.

Tirronen, V., \& Isomöttönen, V. (2011). Making teaching of programming learning-oriented and learnerdirected. In: 11th Koli Calling International Conference on Computing Education Research. ACM Press, Koli, Finland.

Topping, K. J. (1996). The effectiveness of peer tutoring in further and higher education: A typology and review of the literature. Higher Education, 32(3), 321-345.

Vihavainen, A., Paksula, M., et al. (2011). Extreme apprenticeship method in teaching programming for beginners. In: 42nd ACM Technical Symposium on Computer Science Education. ACM Press, New York, NY, USA, pp. 93-98.

Walker, J. S. (2012). The use of saturation in qualitative research. Canadian Journal of Cardiovascular Nursing, 22(2), 37-46.

Wenger, M. S., \& Hornyak, M. J. (1999). Team teaching for higher level learning: A framework of professional collaboration. Journal of Management Education, 23(3), 311-327.

Wilson, V. A., \& Martin, K. M. (1998). Practicing what we preach: Team teaching at the college level. In: Annual Meeting of the Association of Teacher Educators Dallas, Texas, USA, pp. 1-13.

Yanamandram, V. K., \& Noble, G. (2006). Student experiences and perceptions of team-teaching in a large undergraduate class. Journal of University Teaching and Learning Practice, 3(1), 49-66. 